\title{
Prospective cost analysis of laparoscopic vs. open pyeloplasty in children: Single centre contemporary evaluation comparing two procedures over a l-year period
}

\author{
Katherine Moore, MD; ${ }^{\dagger}$ Armando J. Lorenzo, MD, FRCSC;, Suzanne Turner, MD; ; Darius J. Bägli, MD, FRCSC;,* \\ Joao L. Pippi Salle, MD, FRCSC; ${ }^{*}$ Walid A. Farhat, MD, FRCSC
}

*Pediatric Urologist, Division of Urology, The Hospital for Sick Children, University of Toronto, Toronto, ON; †Division of Urology, Centre Hospitalier Universitaire de Quebec, Pavillon CHUL, Quebec, QC

See related article on page 99

Cite as: Can Urol Assoc J 2013;7:94-8. http://dx.doi.org/10.5489/cuaj.11096. Epub 2012 Jan 24.

\begin{abstract}
Introduction: Laparoscopy in pediatric urological surgery continues to gradually gain acceptance. Since economic implications are of increasing importance in our cost-containment environment, few studies have compared the expense associated with open to laparoscopic approaches. We present a prospective comparative cost-analysis between the laparoscopic (LP) and open pediatric pyeloplasty (OP).

Methods: Over a period of a year (2007-2008), 54 consecutives pyeloplasties were performed. The "traditional" OP was performed in 33 patients and the remaining 21 children underwent LP. Costs were prospectively collected for each group and divided based on amounts incurred by all different departments involved: nursing, laboratory, diagnostic imaging, pharmacy and operative room.

Results: Overall, the average cost for a LP was CDN\$6240 compared to CDN\$5079 for an OP with a median hospital stay of 2 days (range OP: 1-18, LP: 1-7). The main difference was found in operative room expenses (OP: \$2508 vs. LP: \$3925). The higher cost could not be solely explained by the use of disposable items, which only subtracts $\$ 335$ per procedure $(23.6 \%$ of the cost difference between OP and LP). Length of time spent in the operating room was 1.2 hours longer for the LP and appears to be the main factor explaining the cost difference.

Conclusion: Our findings show that at our institution, pediatric LP is more expensive than OP. This cost difference is mainly due to operating room time. For cost-containment purposes, efforts aimed at increasing efficiency in the operating room may help equalize both approaches.
\end{abstract}

\section{Introduction}

Options for the surgical management of ureteropelvic junction (UPJ) obstruction have evolved dramatically over the past 20 years in response to the growing development of new technologies. Open pyeloplasty has been the traditional gold standard, while less invasive endoscopic treatments (endopyelotomy, balloon dilatation) have been introduced, albeit with lower success rates. ${ }^{1,2}$ Laparoscopic pyeloplasty has shown success rates comparable to those of open pyeloplasty, while maintaining many advantages of less invasive endoscopic approaches. ${ }^{1-6}$ On the other hand, the cost associated with laparoscopic approaches and the use of associated technical innovations have in turn slowed down their acceptance rate as being the treatment of choice for UPJ obstruction. For instance, the prolonged operating room times with laparoscopic surgeries and its associated learning curve, as well as the costs coupled with disposable instrumentation, have lead to the perception that some of the economic burdens of laparoscopic surgery are inhibitory.

A public health system demands appropriate resource allocation, such as the best use of operating room time and financial resources. Tighter budgetary constraints have resulted in narrow operating room margins, which may threaten the future of minimally invasive procedures. Given that economic implications are of increasing importance in our cost-containment environment, surprisingly few studies have compared the expenses associated by open and laparoscopic techniques.

We hypothesized that initial costs related to laparoscopic surgery are higher, but amenable to strategies that may eventually result in the laparoscopic approach comparing favourably with open surgery. To explore this issue, we present a prospective comparative cost-analysis between the laparoscopic and open approaches for pediatric pyeloplasty. We wanted to determine the precise variables that may be 
modified or what will help in the procedural selection for a given patient demographic to optimize cost-containment.

\section{Methods}

This research was conducted following an initiative by our institution to review the costs incurred by the introduction of new technologies, such as laparoscopy. After approval by the Research Ethics Board, we prospectively collected demographic, operative, recovery and economic data on all consecutive pediatric primary dismembered pyeloplasties performed in a 12-month period by the 5 pediatric urologists at our institution. They were either performed open or laparoscopically, based on surgeon's and parental or patient preference. The endoscopic approach is not considered at our institution as primary treatment for UPJ obstruction in children, thus no formal comparison could be performed with this modality. All costs were prospectively and independently added by each department, ultimately de-identified and reported separately. To simplify the analysis, we excluded surgeons and anesthesia fees, as they tended to be uniformly reimbursed following standard government-issued reimbursing schemes. We also concentrated on operative and hospital stay periods; preoperative and postoperative clinical visits and adjuvant procedures (such as stent removals) were not included. Thus, we assumed similar costs incurred for these items. Cost differences related to the use of externalized versus double-J stents have been previously evaluated at our institution and reported for open pyeloplasties. $^{7}$

A total of 54 pyeloplasties were conducted between April 2007 and March 2008. There were 33 open approaches and 21 laparoscopic transperitoneal dismembered pyeloplasties. These cases reflect a contemporary series performed in a well-established medical practice where the laparoscopic approach has been conducted for a reasonable period of time, beyond the expected necessary learning curve. ${ }^{8}$ The diagnosis of UPJ obstruction was established on the basis of progressive or symptomatic hydronephrosis and obstructive parameters on MAG-3 lasix scan.

\section{Cost analysis}

The pyeloplasty costs were divided and collected by the respective departments. They included operating room costs in 30-minutes intervals, nursing care, surgical supplies, laboratory, pharmaceuticals, diagnostic imaging and in-patient fees. The length of stay in the hospital was counted in whole days from the day of surgery to the day of discharge. All costs were determined as of March 2008. The costs of disposable instruments were derived from the specific price lists of instruments used for the laparoscopic technique. All costs are expressed in Canadian dollars (CDN\$).

\section{Statistics}

Results were entered into an Excel database (Microsoft Corporation, Bellevue, WA). We used an unpaired, heteroscedastic, two-tailed $t$-test to compare groups with respect to continuous variables. Values of $p<0.05$ were considered statistically significant.

\section{Results}

\section{Patient demographics}

There were 42 boys and 12 girls in the study, with an equal percentage of male and females in both surgical groups. The average age of the patients who underwent an open approach was 17 months (range: 2-149), while the average age at the laparoscopic procedure was significantly higher at 125 months (range: 36-204, $p<0.05$ ). Like the age discrepancy, the average weight was also significantly different between the open and the laparoscopic group (10.5 kg \pm 4.3 vs. $38.4 \mathrm{~kg} \pm 21.5 ; p<0.05)$. In the open group, the most common indication for pyeloplasty was obstructive high-grade hydronephrosis, with preoperative ultrasound scan showing grade III hydronephrosis in $48.1 \%$ and grade IV in $51.9 \%$ of patients, according to the Society of Fetal Urology classification system. ${ }^{9}$ In the laparoscopic group, most patients underwent surgery as a result of symptomatic obstruction. There was no statistical difference in the percent function of the affected kidney on preoperative MAG-3 lasix scan when the open group was compared to the laparoscopic group ( $42 \%$ vs. $45 \%$; $p=0.43$ ). The open and laparoscopic procedures were more often $(70 \%$ in both surgical groups) performed on the left-sided kidney (Table 1).

\begin{tabular}{lcc}
\hline Table 1. Patient demographics and disease characteristics \\
\hline Characteristics & Open approach & $\begin{array}{c}\text { Laparoscopic } \\
\text { approach }\end{array}$ \\
\hline No. patients & 33 & 21 \\
Gender (M:F) & $26(79 \%): 7$ & $16(76 \%): 5$ \\
Median age at surgery & $(21 \%)$ & $(23 \%)$ \\
(months) & 17 & 125 \\
Side (L:R) & $23(70 \%): 10$ & $15(71 \%): 6$ \\
Prenatal diagnosis & $(30 \%)$ & $(29 \%)$ \\
\hline Presentation & 14 & 1 \\
Progressive hydronephrosis & 26 & 5 \\
Pain & 3 & 15 \\
Grade of hydronephrosis: III & $18(55 \%)$ & $8(38 \%)$ \\
Grade of hydronephrosis: IV & $14(42 \%)$ & $45 \%$ \\
Median preoperative & $42 \%$ & \\
differential renal function & & $12 \%)$ \\
\hline M: male; F: female; L: left; R: right. & & \\
\hline
\end{tabular}


Moore et al.

\begin{tabular}{|c|c|c|}
\hline & Open & Laparoscopic \\
\hline No. cases & 33 & 21 \\
\hline Median OR time (min) & $\begin{array}{l}131 \text { (range: } \\
82-210 \text { ) }\end{array}$ & $\begin{array}{l}217 \text { (range: } \\
86-360 \text { ) }\end{array}$ \\
\hline Retrograde pyelogram & $25(76 \%)$ & $12(57 \%)$ \\
\hline $\begin{array}{l}\text { Narcotic infusion, epidural, } \\
\text { PCA }\end{array}$ & $10(34 \%)$ & $5(23 \%)$ \\
\hline Average length of stay (days) & 3 (range: 1-18) & 3 (range: 1-7) \\
\hline Median length of stay (days) & 2 (range: 1-18) & 2 (range: 1-7) \\
\hline Stent insertion & $\begin{array}{c}33(100 \%) \\
7 \text { externalized } \\
\text { and } 26 \text { double } J\end{array}$ & $\begin{array}{c}20(95 \%) \\
20 \text { double J }\end{array}$ \\
\hline $\begin{array}{l}\text { Average length of stent } \\
\text { (months) }\end{array}$ & 2 & 2 \\
\hline Median follow-up (months) & 12 (range: 3-19) & 11 (range: 5-28) \\
\hline
\end{tabular}

\section{Intraoperative and postoperative parameters}

Patients spent more time in the operating room when the procedures was performed laparoscopically (217 min; range: 86-360) compared with the open approach (131 min; range: $82-210 ; p<0.05)$. Also following surgeon preference, retrograde pyelogram was more often conducted prior to an open surgery (76\% vs. 57, $p<0.05)$. This follows differential preference for this diagnostic modality by participating surgeons. Being a debatable aspect of intra-operative surgical decision-making, analysis of costs did not take into account this particular practice and operating room time was considered a global figure from time of induction until transfer to the post-anesthesia care unit. A stent was left in place at the end of the anastomosis in all cases, except one in the laparoscopic group. No intraoperative or postoperative adverse events were identified, and no open conversions were necessary in the laparoscopy group.

The median length of postoperative hospital stay was 2 days in both groups. After open pyeloplasty, the patients (in general. younger) stayed between 1 to 18 days, while the laparoscopic hospital stay ranged from 1 to 7 days. There were no complications in either group in the immediate postoperative period and no complications associated with the different approaches. The consumption of narcotics in the form of either infusion, epidural or patient-controlled analgesia (34.5\% vs. $23.8 \%$ ) was greater for the patients in the open approach group, even though it was always prescribed pre-emptively. The average follow-up period was not statistically different; 10 months for the open group versus 12 months (Table 2).

\section{Cost analysis}

The overall costs at our institution for an open pyeloplasty were $\$ 5079$ compared to $\$ 6240$ for the laparoscopic

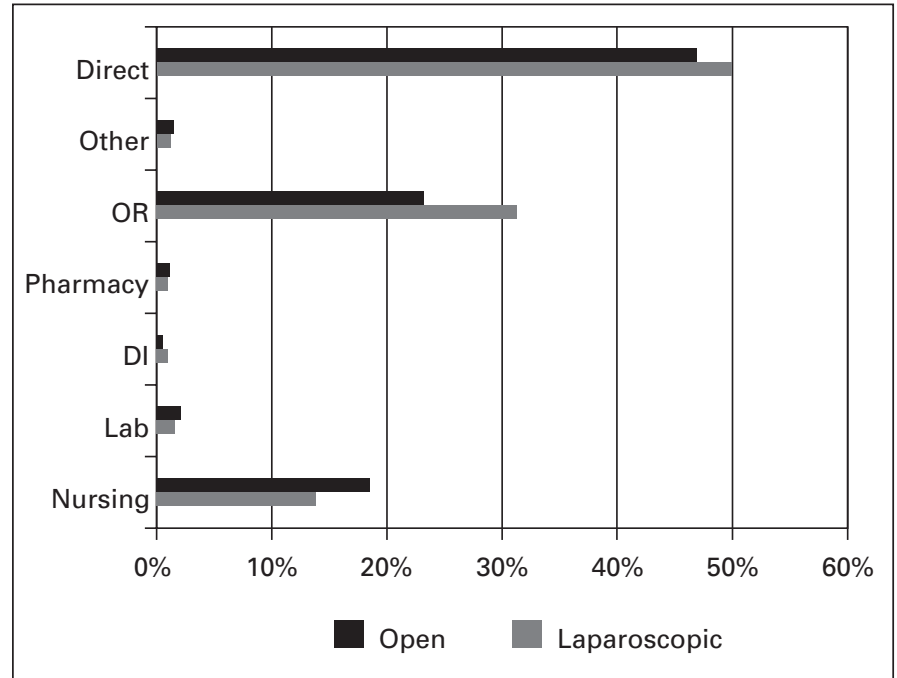

Fig. 1. Percent total cost comparisons by procedure type.

approach, excluding the physician's fees. The mean operating room cost was significantly less in the open surgery group; $\$ 2508$ versus $\$ 3924$ ( $p<0.05$ ). Operating room expenses accounted for $23 \%$ of the total surgical costs in the open group versus $31 \%$ of total costs in the laparoscopic group. This difference is reflected primarily in the longer operating room time, as well as the use of disposable equipment (\$335) required for laparoscopic surgeries. The standard disposable supplies accounted for $2.7 \%$ of the total cost of the laparoscopic surgeries, while there were no equivalent costs in the open surgeries. Nursing, laboratory, pharmacy and direct costs were not statistically different between the two groups (Fig. 1). As the average length of stay was similar in the two groups, there were no substantial differences in the mean hospitalization costs between the two groups.

\section{Discussion}

The widespread introduction of laparoscopic surgeries has been associated with increasing costs, in large part due to longer operating times and the use of disposable instrumentation. ${ }^{4}$ Confirmation of these higher costs is essential for developing a cost-containment strategy. Nevertheless, this may not necessarily always be the case. For example, some have described lower costs of laparoscopic simple and partial nephrectomies compared to the open procedure..$^{5,10}$ When considering global cost analysis, increased operative expenses should optimally be offset by other parameters of similar weight, such as hospital stay. However, in recent years, the length of postoperative hospitalization has tended to shorten no matter which operative approach is chosen. Particularly in children, hospital stay is generally short and recovery fast, making it more difficult for the proponents of laparoscopy to claim cost-savings. ${ }^{11}$

Previous studies have validated the concept that the first step in cost-containment involves identifying variables that 


\begin{tabular}{lcc}
\hline Table 3. Departmental costs & & \\
\hline Expenses (CDN\$) & Open & Laparoscopic \\
\hline Nursing & 1999 & 1716 \\
Laboratory & 229 & 201 \\
Diagnostic imaging & 58 & 118 \\
Pharmacy & 121 & 126 \\
Operating room & 2508 & 3925 \\
Total (CDN\$) & $\mathbf{5 0 7 9}$ & $\mathbf{6 2 4 0}$ \\
\hline
\end{tabular}

contribute to overall costs. ${ }^{12}$ As expected, in this present analysis the higher costs associated with laparoscopic pyeloplasty were due to longer operating time, as well as the added cost of disposables. These variables are potentially open to improvement, particularly by evaluating efficiency in conducting laparoscopic procedures. Importantly, it must be remembered that in the current study the type of stent used did not appear to influence differences in cost. Although technical advances allow for the safe placement of externalized pyeloureteral stents (such as the Salle intraoperative pyeloplasty stent, Cook Urological, Spencer, IN), the current practice is to place standard double-J ureteral stents in these cases. A formal comparative analysis of these two devices has been previously conducted for open procedures, ${ }^{7}$ and an overall cost advantage favouring the externalized stent is reasonable. All other variables, including nursing care, laboratory, pharmacy and diagnostic imaging costs, were not statistically different when comparing the two surgical groups (Fig. 1).

As the surgical technique for pyeloplasty evolves and simplifies, it may be possible to further reduce the use of disposable instrumentation and to decrease overall operating room times. ${ }^{4} \mathrm{~A}$ previous study from our institution examined technical advances in laparoscopic pyeloplasty that were incorporated into the current cases with experienced laparoscopic surgeons in charge of this approach. This represents a simple cost-containment strategy. ${ }^{4}$ Several studies analyzing the costs associated with laparoscopic surgeries have identified that increased costs (compared to open procedures) may depend on the skill of the surgeon, experience and case volume. ${ }^{4,13-17}$ It is likely that with increasing laparoscopic procedure frequency there will be a natural progression to shorter operating room times. The more efficient use of the operating room is dependent on the surgeon, his skills and the use of well-adapted instruments. However, we propose that dedicated nursing and anesthesia teams can help decrease the time spent in the room by the patient; this hypothesis was previously entertained by Kenyon and colleagues. ${ }^{18}$ For the laparoscopic procedure, the positioning of the patient relies on the team effort between the anesthesia, nursing and surgical groups, and can be time-consuming. During the procedure, good knowledge of the equipment by the nursing and surgical teams can save time. Finally, at the end of the procedure, good communication between the sur- gical and anesthesia teams can diminish the time to awaken the patient, as patients are extubated in the operative room at our institution. All these simple changes can easily lead to valuable minutes gained for laparoscopic procedures as well as for open procedures. Given the accounting practices at our institution, only a 30-minute decrease in operating room time would be required to affect this variable. A further drop in cost may be achieved by developing strategies that involve change in practice, such as the forgoing of the retrograde pyelogram or stentless repair.

Studies that prospectively followed the costs associated with evolving laparoscopic techniques imply that active procurement policies, the standardization of operating room procedures and the active use of reusable instruments can reduce costs over time. ${ }^{19}$ As a result of this study, the development of standard operating procedures that address instrumentation and room conversion may decrease operating time. Actively developing procurement strategies that may involve bulk purchasing or group purchasing with other local hospitals may effectively reduce the cost of disposables. However, given the restrictions of many institutions as exclusively pediatric tertiary care facilities, group purchasing opportunities may be limited.

The simple cost-comparison strategy used in this paper has several advantages. The financial data were collected prospectively from a single institution at a single time point and as a result the accounting principles used in assigning variables is consistent for each of the patients studied. Similarly, as all of the financial data were collected within a short timeframe, the monetary units are identical and there is no need to convert, amortize or equalize funds. To capture the fiscal value of quality of life measures, several studies have compared the cost-effectiveness of open and laparoscopic surgeries. ${ }^{20}$ In the adult population, Baldwin and colleagues report greater cost-effectiveness of the laparoscopic pyeloplasty over Acucise (Applied Medical, Rancho Santa Margarita, CA) endopyelotomy and the open approach even if it generates more initial operative expenses. ${ }^{1}$ Indeed, costeffectiveness reflects direct cost of the procedure, but also takes into account success rate and additional investigation and treatment. Bhayani and colleagues compared robotic to pure laparoscopic pyeloplasty and found that if the laparoscopic procedure was less than 338 minutes, it was more cost-effective that the robotic equivalent. ${ }^{21,22}$ However, we lack utilities and reliable effectiveness data to conduct similar analyses in the pediatric population.

While the benefits of cosmesis for laparoscopic surgeries are widely accepted, there are no standardization in terms of economic evaluation. Furthermore, quality of life measures have not been validated for laparoscopic or open procedures in the pediatric populations. Moreover, caregiver burden and return to work times for parents were not examined in this study and may have provided further insight into overall 
Moore et al.

societal cost benefits. As a result, the simple cost comparison used here only provides standardization, institutional evaluation of the data and more direct extrapolation to other types of institutions and surgical procedures.

This study demonstrates that laparoscopic pyeloplasty has become more often offered to our older population compared to the standard open procedure in our institution and, as a result, the two surgical groups are not age-matched. The open procedure may continue to prevail in the infant and toddler age group due to the technical barriers associated with small abdominal volumes and length of available instruments. Age-matched controls in a prospective, randomized study comparing open to laparoscopic pyeloplasty may have elucidated differences in length of hospital stay and analgesia that may lead to cost equivalency and/or cost reduction in the laparoscopic group. However, the technical challenges of laparoscopy in infants, the demand of parents and ethical expectations make randomization and recruitment very difficult.

We acknowledge the methodological constraints of this analysis. Cost variables may have been confounded by surgeon variability, including technological experience. The data collected here are based on the fee-for-service funding model and market forces typical of the Canadian health care system, and extrapolation of these results may be difficult in the context of a market-based system or in the developing world. This study is of cost-analysis and does not intend to imply data on cost-effectiveness or cost-utility. However, to our knowledge, this is the first cost-analysis of its kind on the topic, comparing open and laparoscopic pediatric pyeloplasties. Future evaluation of the factors presented will likely be of value for implementation of changes that could lead to decreased costs and more efficient use of limited resources.

\section{Conclusions}

Our findings show that at our institution pediatric laparoscopic pyeloplasty is more expensive than the open technique. This cost difference is mainly due to operating room time. For cost-containment purposes, efforts aimed at increasing efficiency in the operating room may help equalize both approaches.

Competing interests: None declared.

This paper has been peer-reviewed.

\section{References}

1. Baldwin DD, Dunbar JA, Wells N, et al. Single-center comparison of laparoscopic pyeloplasty, Acucise endopyelotomy, and open pyeloplasty. J Endourol 2003;7:155-60. http://dx.doi. org/10.1089/089277903321618716

2. Gettman MT, Lotan Y, Roerhborn CG, et al. Cost-effective treatment for ureteropelvic junction obstruction: a decision tree analysis. J Urol 2003; 169:228-32. http://dx.doi.org/10.1016/S0022-5347(05)64074-8

3. Bauer JJ, Bishoff JT, Moore RG, et al. Laparoscopic versus open pyeloplasty: assessment of objective and subjective outcome. J Urol 1999;162:692-5. http://dx.doi.org/10.1097/00005392-19990901000016

4. Braga LH, Pippi-Salle J, Lorenzo AJ, et al. Pediatric laparoscopic pyeloplasty in a referral center: lessons learned. J Endourol 2007;21:738-42. hittp://dx.doi.org/10.1089/end.2006.0420

5. Cervellione RM, Gordon $M$, Hennayake $S$. Financial analysis of laparoscopic versus open nephrectomy in the pediatric age group. J Laparoendosc Adv Surg Tech A 2007;17:690-2. http://dx.doi.org/10.1089/ lap.2007.0015

6. Penn HA, Gatti JM, Hoestie SM, et al. Laparoscopic versus open pyeloplasty in children: preliminary report of a prospective randomized trial. J Urol 2010;184:690-5. http://dx.doi.org/10.1016/i. juro.2010.03.062

7. Braga LH, Lorenzo AJ, Farhat WA, et al. Outcome analysis and cost comparison between externalized pyeloureteral and standard stents in 470 consecutive open pyeloplasties. J Urol 2008; 180:1693-8; discussion 1698-9

8. Singh 0 , Gupta SS, Arvind NK. Laparoscopic pyeloplasty: an analysis of first 100 cases and important lessons learned. Int Urol Nephrol 2011;43:85-90. Epub 2010 May 21. htrp://dx.doi.org/10.1007/ s1 1255-010-9753-4

9. Fernbach SK, Maizels M, Conway JJ. Ultrasound grading of hydronephrosis: introduction to the system used by the Society for Fetal Urology. Pediatr Radiol 1993;23:478-80. htrp://dx.doi.org/10.1007/ BF02012459

10. Park S, Pearle MS, Cadeddu JA, et al. Laparoscopic and open partial nephrectomy: cost comparison with analysis of individual parameters. J Endourol 2007;21:1449-54. http://dx.doi.org/10.1089/ end.2007.9873

11. Esposito C, Corcione F, Garipoli V, et al. Pediatric laparoscopic splenectomy: are there real advantages in comparison with the traditional open approach? Pediatr Surg Int 1997;12:509-10. http://dx.doi. org/10.1007/BF01258713

12. Lotan Y, Gettman MT, Roehrborn CG, et al. Cost comparison for laparoscopic nephrectomy and open nephrectomy: analysis of individual parameters. Urology 2002;59:821-5. http://dx.doi.org/10.1016/ S0090-4295(02)01611-4

13. Allen JW, Polk HC Jr. A study of added costs of laparoscopic cholecystectomy based on surgery preference cards. Am Surg 2002;68:474-6.

14. Cookson R, Flood C, Koo B, et al. Short-term cost effectiveness and long-term cost analysis comparing laparoscopic Nissen fundoplication with proton-pump inhibitor maintenance for gastro-oesophageal reflux disease. Br J Surg 2005;92:700-6. hittp://dx.doi.org/10.1002/bjs.4933

15. Luks Fl, Logan J, Breuer CK, et al. Cost-effectiveness of laparoscopy in children. Arch Pediatr Adolesc Med 1999; 153:965-8.

16. Oldham KT. Financial considerations in laparoscopic and open appendectomy. Arch Pediatr Adolesc Med 2004;158:11-2. htrp://dx.doi.org/10.1001/archpedi.158.1.11

17. Peters CA. The evolution of laparoscopy in pediatric urology-intelligent design? I Urol 2006;175:1993-4. http://dx.doi.org/10.1016/i.juro.2006.03.015

18. Kenyon TA, Lenker MP, Bax TW, et al. Cost and benefit of the trained laparoscopic team. A comparative study of a designated nursing team vs a nontrained team. Surg Endosc 1997;11:812-4. hitp://dx.doi. org $/ 10.1007 / 5004649900460$

19. Mahomed AA, McLean V. Cost analysis of minimally invasive surgery in a pediatric setting. J Laparoendosc Adv Surg Tech A 2007;17:375-9. http://dx.doi.org/10.1089/lap.2006.0077

20. Hamidi V, Andersen MH, Oyen 0 , et al. Cost effectiveness of open versus laparoscopic living-donor nephrectomy. Transplantation 2009;87:831-8. http://dx.doi.org/10.1097/TP.0b013e318199cfc9

21. Bhayani SB, Link RE, Varkarakis JM, et al. Complete daVinci versus laparoscopic pyeloplasty: cost analysis. J Endourol 2005; 19:327-32. http://dx.doi.org/10.1089/end.2005.19.327

22. Link RE, Bhayani SB, Kavoussi LR. A prospective comparison of robotic and laparoscopic pyeloplasty. Ann Surg 2006;243:486-91. htrp://dx.doi.org/10.1097/01.sla.0000205626.71982.32

Correspondence: Dr. Walid A Farhat, Division of Urology, The Hospital for Sick Children, University of Toronto, 555 University Ave., Toronto, ON M5G 1X8; fax: 416-813-6461; walid.farhat@sickkids.ca 